
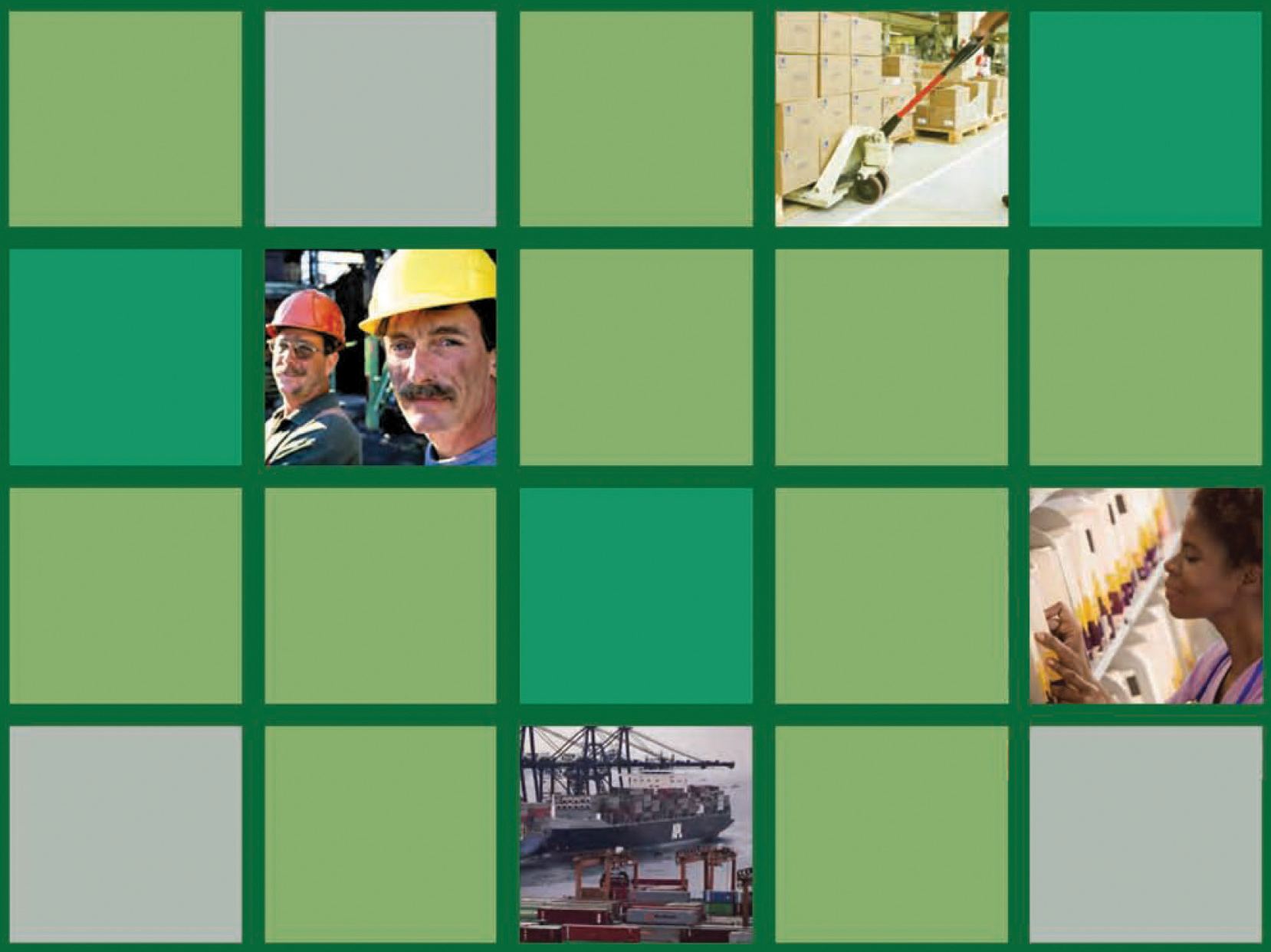

\title{
Directrices para reportar la ocupación y el tipo de industria en los certificados de defunción
}


Esta página se dejó en blanco de manera intencional. 


\section{Directrices para reportar la ocupación y el tipo de industria en los certificados de defunción}

Autores

Cynthia Robinson, Pam Schumacher, Marie Haring Sweeney, Andrea L. Steege, Hannah Free y Jose Lainez escribieron este documento 
Este documento es de dominio público y se puede reproducir o reimprimir libremente.

\section{Descargo de responsabilidad}

La mención de cualquier empresa o producto no constituye respaldo alguno por parte del Instituto Nacional para la Seguridad y Salud Ocupacional (NIOSH). Además, la mención de las páginas de Internet externas a NIOSH no constituye un respaldo por parte de NIOSH a las organizaciones patrocinadoras ni a sus programas o productos. De igual manera, NIOSH no se responsabiliza por el contenido de esos sitios web. Hasta la fecha de publicación de este documento se podía ingresar a todos los sitios web mencionados como referencia.

\section{Obtenga más información}

Encuentre materiales de NIOSH y obtenga respuestas a las preguntas sobre seguridad y salud en el lugar de trabajo:

1-800-CDC-INFO (1-800-232-4636) | Linea TTY: 1-888-232-6348

CDC/NIOSH INFO: cdc.gov/info |cdc.gov/niosh

Boletín mensual de NIOSH eNews: cdc.gov/niosh/eNews

\section{Cita recomendada}

NIOSH [2021]. Directrices para reportar la ocupación y el tipo de industria en los certificados de defunción. Por Robinson C, Schumacher P, Sweeney MH, Steege AL, Free H, Lainez J. Cincinnati, OH: U.S. Departamento de Salud Y Servicios Humanos, Centros para el Control y la Prevención de Enfermedades, Instituto Nacional para la Seguridad y Salud Ocupacional, DHHS (NIOSH) Publicación núm. 2012-149spa (revisado 01/2021)

DOI: https://doi.org/10.26616/NIOSHPUB2012149sparevisado012021

DHHS (NIOSH) Publicación No. 2012-149spa (revisado 01/2021)

Enero 2021

Este documento se revisó para actualizar las referencias de sitios web y direcciones electrónicas. No se hicieron cambios importantes en la información que contiene este documento. 


\section{Agradecimientos}

NIOSH agradece a los directores funerales, la Asociación Nacional de Estadísticas y Sistemas de Información de Salud Pública (NAPHSIS), el Centro Nacional de Estadísticas de Salud (NCHS), y los departamentos de salud estatales por su papel fundamental en la elaboración de declaraciones de ocupación e industria precisas y completas.

También quisiéramos agradecer a la Asociación Nacional de Directores de Funerales (NFDA), el Centro Nacional de Estadísticas de Salud (NCHS) y el Instituto Universitario de Ciencias Mortuorias de Cincinnati por sus aportes cuando los consultamos para elaborar este documento. 
Esta página se dejó en blanco de manera intencional. 


\section{Contenido}

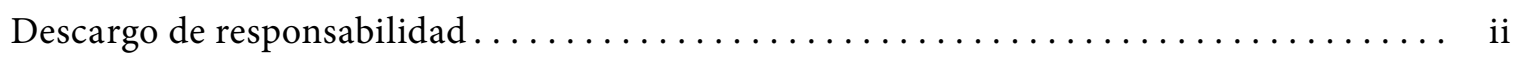

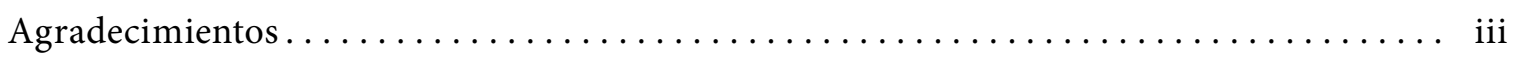

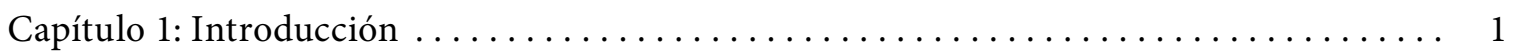

La importancia de recolectar la información sobre la ocupación y el tipo de industria. 2

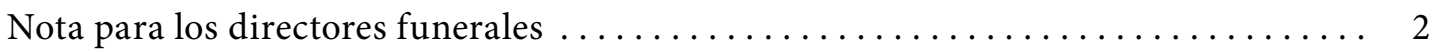

Capítulo 2: Cómo completar los certificados de defunción ............... 3

¿Quién da la información sobre la ocupación y el tipo de industria? ........... 3

Cómo obtener la mejor información $\ldots \ldots \ldots \ldots \ldots \ldots \ldots \ldots \ldots \ldots \ldots \ldots \ldots \ldots \ldots \ldots \ldots \ldots \ldots \ldots$

Capítulo 3: Reglas para reportar la ocupación habitual y el tipo de empresa o industria... 5

Reglas básicas .................................. 5

Reglas para situaciones especiales. ........................ 5

Capítulo 4: Cómo completar la información sobre la ocupación. .............. 9

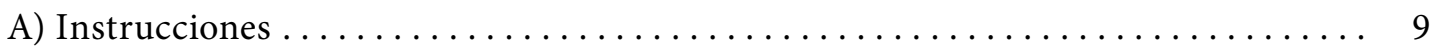

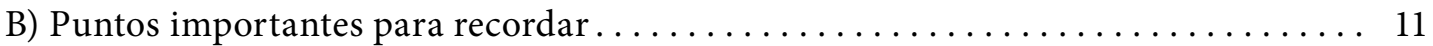

C) Ocupaciones genéricas que se reportan con frecuencia y podrían requerir

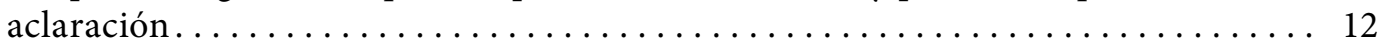

D) Ocupaciones que se confunden comúnmente y requieren aclaración: . . . . . 13

Capítulo 5: Cómo completar la información sobre el tipo de empresa o industria $\ldots \ldots \ldots 15$

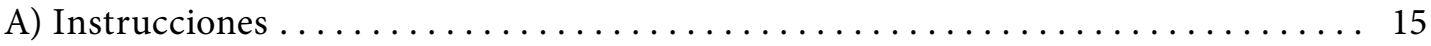

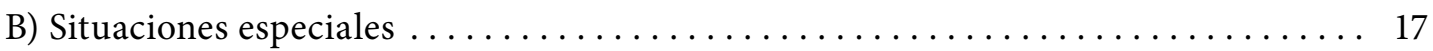

Capítulo 6: Situaciones en las que hubo varios trabajos a lo largo de la vida . . . . . . . . 19

Capítulo 7: Lista de verificación: cómo revisar la información que ha ingresado . . . . . 21

Apéndice A: Ejemplos de información ingresada sobre la ocupación que requiere más detalles. . . . . . . . . . . . . . . . . . . . . . . . . . . . . 23

Apéndice B: Ejemplos de información ingresada sobre la industria que requiere más

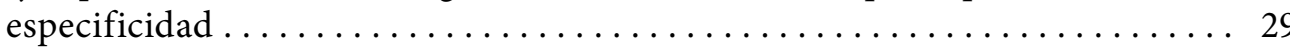

Apéndice C: Ejemplos de información ingresada de forma aceptable sobre la ocupación

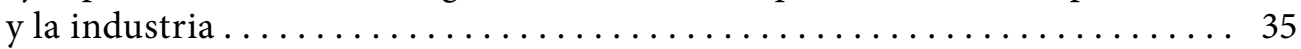

Apéndice D: El Sistema de Registro de Estadísticas Vitales en los Estados Unidos . . . . . 37

Cómo usar los datos sobre muertes para las acciones de salud pública $\ldots \ldots \ldots \ldots 38$ 
Esta página se dejó en blanco de manera intencional. 


\section{Capítulo 1 \\ Introducción}

$\mathrm{Al}$ reportar datos precisos sobre el tipo de industria y la ocupación en la que la persona fallecida se desempeñó habitualmente o a lo largo de la vida, los directores funerales y quienes participan en el proceso de registro ayudan a mejorar las estadísticas sobre la mortalidad ocupacional y la salud de los trabajadores. Este documento actualiza las directrices que el Centro Nacional de Estadísticas de Salud (NCHS) redactó en 1988 (DHHS Publication No. 88-1149) y el Instituto Nacional para la Seguridad y Salud Ocupacional (NIOSH) revisó en el 2012 (DHHS Publication No. 2012-149) y el 2020. El documento está diseñado para ayudar a los directores funerales a completar, en los certificados de defunción electrónicos o en papel, la información sobre la ocupación habitual y el tipo de empresa o industria relacionada con la persona fallecida. NIOSH codifica y revisa la ocupación y el tipo de industria que reportan las jurisdicciones, combina esta información con los datos de mortalidad del NCHS, y reporta las tendencias en mortalidad ocupacional en los Estados Unidos.

En los Estados Unidos, el trabajador o la trabajadora promedio pasa una parte importante de su vida en el trabajo. El lugar de trabajo podría exponer a los trabajadores a riesgos o peligros que pueden contribuir a que se presenten lesiones o enfermedades. La información sobre el trabajo y el tipo de empresa en la que se desempeñó una persona brinda un panorama general sobre los peligros laborales que podría haber afrontado. Las enfermedades podrían aparecer inmediatamente o muchos años después de que los trabajadores hayan dejado su puesto. Los datos sobre la ocupación y el tipo de industria en la que se desempeñaron los trabajadores pueden señalar los riesgos para la salud a los que podrían haber estado expuestos.

En los Estados Unidos, cada año se reportan aproximadamente 5000 muertes traumáticas relacionadas con el trabajo y decenas de miles de muertes relacionadas con el trabajo que son causadas por enfermedades. Se ha sabido por muchas décadas que las exposiciones a peligros en el entorno laboral pueden causarles a los trabajadores lesiones o enfermedades graves y la muerte.

Es importante registrar respuestas de alta calidad, precisas y completas en los certificados de defunción de todas las personas fallecidas de 14 años y mayores que hayan estado empleadas, desempleadas o jubiladas. Esos datos pueden usarse para tomar decisiones que tengan como fin crear entornos laborales más seguros y saludables. 


\section{La importancia de recolectar la información sobre la ocupación y el tipo de industria}

Los planificadores e investigadores de salud pública cuentan con los directores funerales para que registren la mejor información posible sobre los factores potenciales de riesgo, incluidos los trabajos potencialmente peligrosos que tuvieron las personas fallecidas durante su vida laboral.

La ocupación habitual (la que tuvieron durante más tiempo) y el tipo de empresa o industria de los trabajadores pueden revelar la carga nacional de enfermedades y lesiones, por industria y ocupación. Esa información también puede usarse para ayudar a descubrir los trabajos que podrían tener un riesgo alto de muerte debido a lesiones, cáncer $u$ otras enfermedades, y en torno a los cuales se pueden concentrar o dirigir los esfuerzos de prevención.

\section{Nota para los directores funerales}

Entendemos que los directores funerales muchas veces se ven limitados por la cantidad y especificidad de la información que reciben de las personas cercanas al fallecido, pero creemos que los consejos que se presentan a continuación serán útiles. Los ejemplos que se describen como "adecuados" siempre se prefieren antes que la información ingresada que se describe como "inadecuada", pero la información ingresada que se considera "inadecuada" es aceptable cuando no haya otra información disponible. En este folleto usamos el término "inadecuada" para describir la información ingresada que no brinda suficientes datos para una codificación precisa del tipo de industria u ocupación, según los sistemas estándar de clasificación. 


\section{Capítulo 2 \\ Cómo completar los certificados de defunción}

\section{¿Quién da la información sobre la ocupación y el tipo de industria?}

La persona que proporciona la información sobre el fallecido debe ser alguien que conozca de primera mano sus antecedentes laborales. Esta persona, a la que de aquí en adelante llamaremos el informador, debe poder describir de forma precisa los tipos de trabajos que tuvo el fallecido durante su vida.

El informador es generalmente el o la cónyuge o un pariente de primer grado (padres, hermanos o hijos). Otros familiares o amigos podrían proporcionar detalles sobre la ocupación habitual o de mayor duración y el tipo de empresa o industria de la persona fallecida.

\section{Cómo obtener la mejor información}

Si la persona fallecida tuvo muchas ocupaciones distintas y trabajó en diferentes tipos de empresas, podría ser necesario hacer preguntas como las que se presentan a continuación para determinar la ocupación habitual y el tipo de industria:

- ¿En qué trabajo se desempeñó durante más tiempo el fallecido?

- ¿Qué tipo de trabajo hizo el fallecido durante más años en su vida?

- Si la persona fallecida tuvo varios trabajos a lo largo de su vida, ¿en cuál trabajo se desempeñó durante más tiempo? 
Esta página se dejó en blanco de manera intencional. 


\section{Capítulo 3}

\section{Reglas para reportar la ocupación habitual y el tipo de empresa o industria}

\section{Recuerde}

Siempre habrá un tipo de empresa o industria que corresponda a la información ingresada sobre ocupación habitual.

En este capítulo se discuten las reglas para reportar la ocupación habitual y el tipo de empresa o industria correspondientes a las personas que alguna estuvieron empleadas en su vida. Tal vez algunas personas fallecidas no hayan estado nunca en la fuerza laboral, pero si alguna vez estuvieron empleadas, debería haber una ocupación habitual para reportar. Las siguientes reglas brindan una guía sobre lo que debe reportarse en esas situaciones y en las respuestas como, por ejemplo, niño, persona que hace tareas domésticas o jubilado, entre otras.

\section{Reglas básicas}

1. Si la persona fallecida estuvo alguna vez empleada, siempre complete la información sobre ocupación habitual y tipo de empresa o industria.

2. No deje ningún casillero en blanco donde se pida información sobre la ocupación y el tipo de empresa o industria.

\section{Reglas para situaciones especiales}

1. Si la persona fallecida tenía menos de 14 años de edad, ingrese "bebé"o "niño" en el casillero sobreocupación o tipo de empresa o industria.

2. Estudiante (14 años de edad o mayor):

- Estudiante de tiempo completo que no trabajaba:

o Ingrese "estudiante" en el casillero de ocupación habitual.

o Ingrese el tipo de institución educativa, como "escuela secundaria superior" o "universidad" en el casillero de tipo de empresa o industria.

- Estudiante de tiempo parcial que también trabajaba (media jornada o jornada completa):

o Ingrese su ocupación habitual y el correspondiente tipo de empresa o industria. 
Ejemplos de empleados por cuenta propia

\begin{tabular}{lc}
\hline $\begin{array}{c}\text { Ocupación } \\
\text { habitual }\end{array}$ & $\begin{array}{c}\text { Tipo de empresa } \\
\text { o industria }\end{array}$ \\
\hline Zapatero & $\begin{array}{c}\text { Zapatero } \\
\text { empleado por } \\
\text { cuenta propia }\end{array}$ \\
Reparador/ & $\begin{array}{c}\text { Reparador/técnico } \\
\text { empleado por } \\
\text { écnico }\end{array}$ \\
cuenta propia \\
Pintor de autos & $\begin{array}{c}\text { Pintor de autos } \\
\text { empleado por } \\
\end{array}$ \\
& cuenta propia \\
\hline
\end{tabular}

\section{Jubilado, retirado: Nunca ingrese "jubilado" ni} "retirado". Si la persona fallecida era jubilada, ingrese el tipo de trabajo que hizo durante la mayor parte de su vida laboral.

4. Desempleado: Nunca ingrese "desempleado". Ingrese la ocupación habitual y el tipo de empresa o industria de la persona fallecida si alguna vez estuvo empleada. Si la persona nunca trabajó, use la regla \#8 (Nunca trabajó).

5. Se desconoce: Se debe ingresar esto solamente después de que se haya hecho todo esfuerzo posible para determinar la ocupación habitual y el tipo de empresa o industria. Se desconoce debe ser la última opción y debe ingresarse tanto para ocupación habitual como para tipo de empresa o industria.

6. Empleado por cuenta propia: Si la persona estaba empleada por cuenta propia, ingrese el tipo de trabajo que hacía, incluidos la profesión o el oficio, en el casillero de ocupación habitual. Para tipo de empresa o industria, ingrese la ocupación habitual junto al término "empleado por cuenta propia" y repita la ocupación habitual.

7. Discapacitado o internado: Ingrese la ocupación habitual y el tipo de empresa o industria de la persona fallecida si alguna vez estuvo empleada. Si la persona fallecida discapacitada o internada nunca trabajó, aplique la regla \#8 (Nunca trabajó).

8. Nunca trabajó: Si la persona fallecida no era estudiante ni una persona que hace tareas domésticas/ama de casa y nunca había trabajado en su vida, ingrese "Nunca trabajó" para ocupación habitual y tipo de empresa o industria. 
9. Persona que hace tareas domésticas ${ }^{1}$ : Para determinar la información ingresada para la ocupación como "persona que hace tareas domésticas", es importante averiguar lo siguiente sobre la persona fallecida:

a. Si trabajaba por un salario fuera de su casa.

b. Si trabajaba en su propia casa o en la casa de otra persona.

Diagrama de comparación entre persona que hace tareas domésticas /ama de casa y trabajador/a doméstico/a

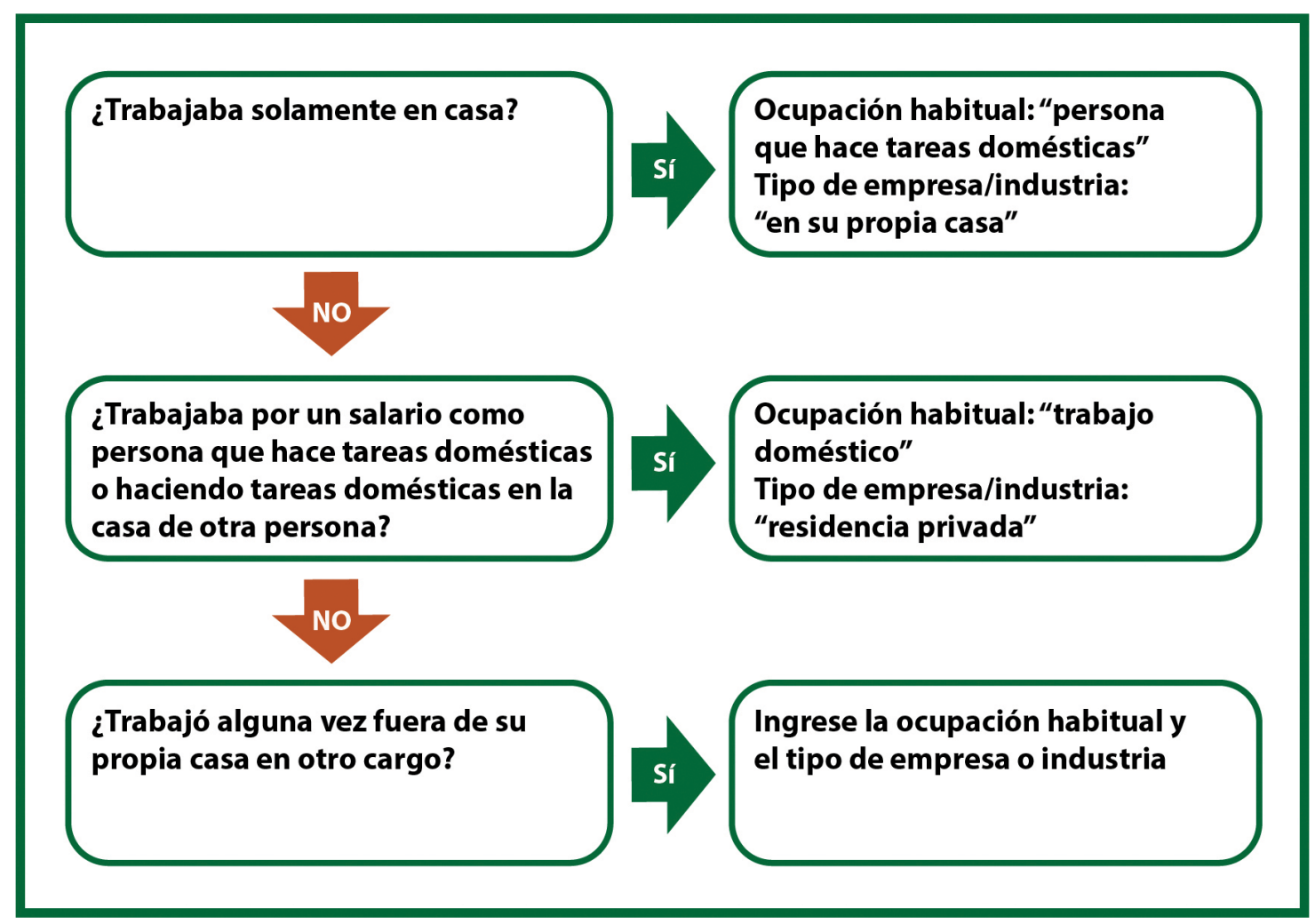

${ }^{1}$ También conocido como "madre que se queda en casa", "padre que se queda en casa" o "cónyuge que se queda en casa/ama de casa". 
Esta página se dejó en blanco de manera intencional. 


\section{Capítulo 4 \\ Cómo completar la información sobre la ocupación}

\section{Definición}

Ocupación habitual de la persona fallecida: Tipo de trabajo que la persona desempeñó durante la mayor parte de su vida o el trabajo que tuvo durante más tiempo.

\section{A) Instrucciones}

En el espacio que el certificado de defunción tiene para la ocupación habitual de la persona fallecida, ingrese la palabra o las palabras que mejor describan el tipo de trabajo o de tareas que la persona fallecida desempeñó durante la mayor parte de su vida laboral.

La siguiente información puede ayudar a determinar la ocupación habitual de la persona fallecida.

- La ocupación habitual se puede obtener al pedirle al informador que identifique el trabajo que la persona tuvo durante más tiempo. Esto corresponde a todas las personas que estuvieron empleadas, desempleadas o jubiladas en algún momento de su vida.

o Si la persona fallecida tuvo varios trabajos, identifique cuál fue el que tuvo durante más años en su vida laboral.

o Cabe destacar que no se trata necesariamente de la última ocupación de la persona fallecida.

o La ocupación habitual podría no ser el trabajo mejor pagado o más prestigioso.

Ingrese en el certificado de defunción el trabajo que haya tenido durante más tiempo. La mejor respuesta debe ser específica y descriptiva. Se deben explicar las tareas y responsabilidades.

\section{Ejemplo de ocupación habitual}

Una mujer trabajó en la cocina de un restaurante de comida rápida durante cinco años. Luego, trabajó como secretaria en un concesionario de autos durante 25 años. Después, trabajó como asistente de cuidados en un establecimiento para jubilados durante 10 años.

¿Cuál es su ocupación habitual y tipo de empresa o industria?

Ocupación habitual: "Secretaria"

Tipo de empresa o industria:

"Concesionario de autos"

Si bien tuvo tres trabajos durante mucho tiempo, su trabajo como secretaria en el concesionario de autos es el que tuvo por más tiempo (25 años). Concesionario de autos es el tipo de empresa donde trabajó como secretaria. 


\section{Capítulo 4: Cómo completar la información sobre la ocupación}

Las siguientes preguntas podrían usarse para obtener información más específica sobre las tareas y responsabilidades:

“¿Qué tipo de trabajo estaba haciendo?” “Cuáles eran sus responsabilidades y tareas específicas?"

“¿Cuánto tiempo había estado haciendo este tipo de trabajo?”

Si la ocupación habitual de la persona fallecida no está clara con base en la información que proporcionó el informador, ingrese algunas palabras que la describan. Vea ejemplos en la tabla 1.

\section{Tabla 1}

El ejemplo que se presenta a continuación muestra nombres generales de ocupaciones; sin embargo, cuanto más específico sea el nombre de la ocupación, mejor será la información ingresada.

\begin{tabular}{ll}
\hline \multicolumn{1}{c}{ General } & \multicolumn{1}{c}{ Más específico } \\
\hline Vendedor & Venta de seguros, venta de publicidad... \\
Asistente & Asistente de oficina, asistente de dentista... \\
Gerente & Gerente de tienda de alimentos, gerente de oficina... \\
Maestro & Maestro de prescolar, maestro de secundaria superior... \\
Agricultor & $\begin{array}{l}\text { Trabajador de finca frutícola, operador de máquina para ordeñar, trabajador } \\
\text { agrícola, arriero... }\end{array}$ \\
\hline
\end{tabular}




\section{B) Puntos importantes para recordar}

Es importante que la información ingresada sobre la ocupación sea muy específica. ${ }^{2}$ Los ejemplos que se presentan a continuación podrían ser útiles cuando se trate de aclarar el nombre impreciso o inusual de una ocupación:

1. Aprendiz o ayudante. Aclare si la persona era aprendiz, practicante o ayudante en su ocupación.

\section{Ejemplos}

- Ayudante de contador

- Ayudante de electricista

- Aprendiz de mecánico de

- Aprendiz de plomero autos

2. Dueño de empresa o negocio. Aclare si la persona fallecida era dueña de una empresa o un negocio. La ocupación habitual del dueño de empresa o negocio no está relacionada necesariamente con el tipo de empresa o negocios.

\section{Ejemplos}

\section{Demasiado general}

- Panadero

- Impresor

- Cervecero

\section{Más específico}

- Dueño de panadería

- Dueño de imprenta

- Dueño de fábrica de cerveza

3. Ocupaciones poco comunes. Ingrese la información que haya dado el informador aunque la ocupación parezca poco común.

\section{Ejemplos}

- “Trabajador subterráneo (sand hog)": trabaja en la construcción de túneles subacuáticos.

- "Aprendiz de imprenta (printer's devil)": se refiere a un aprendiz que trabaja en una imprenta.

- "Reparador de vagones de carga (flatcar whacker)": mantiene y repara vagones de tren que cargan troncos.

- "Alisador de lechos (bed rubber)": opera maquinaria que alisa bloques de roca.

${ }^{2}$ Remítase al apéndice A para ver más ejemplos de nombres de ocupaciones que requieren más detalles 


\section{C) Ocupaciones genéricas que se reportan con frecuencia y podrían requerir aclaración}

Hay muchos nombres de ocupaciones que describen un tipo general de trabajo, como contratista, consultor, ensamblador o técnico. Es importante identificar la naturaleza específica del trabajo desempeñado y el tipo de empresa o industria de la persona fallecida.

1. Contratista. Ingrese el tipo de trabajo que la persona fallecida hacía como contratista.

\section{Ejemplos}

- Contratista agrícola

- Contratista administrativo

- Contratista de plomería

- Contratista en el sector militar

2. Consultor. ¿Qué tipo de consultoría brindaban? El término "consultor" debe incluir una ocupación específica.

\section{Ejemplos}

- Consultor en contabilidad

- Consultor de farmacia

- Consultor en enfermería

- Consultor en computación

- Consultor en alimentación

- Consultor en ventas de pelucas

3. Ensamblador. Incluya el tipo de producto que ensamblaba.

\section{Ejemplos}

- Ensamblador de juguetes

- Ensamblador de motores de camiones

- Ensamblador de electrodomésticos
- Ensamblador de muebles

- Ensamblador de electrónicos

- Ensamblador de edificios de concreto

4. Técnico. Incluya el proceso técnico específico en el que trabajaba la persona fallecida.

\section{Ejemplos}

- Técnico de laboratorio

- Técnico de software médico

- Técnico de farmacia

- Técnico de autos

- Técnico de refrigeración

- Técnico de radio y televisión 
5. Obrero. Incluya el tipo de trabajo que hacía el obrero.

\section{Ejemplos}

- Obrero de almacén

- Obrero de limpieza

- Obrero de la construcción

- Obrero de la industria petrolera

- Obrero agrícola

- Obrero de jardinería

\section{D) Ocupaciones que se confunden comúnmente y requieren aclaración:}

Los nombres de algunas ocupaciones pueden sonar iguales o ser difíciles de dilucidar. Haga preguntas adicionales para asegurarse de ingresar la ocupación correcta. A continuación se presentan los nombres de ocupaciones que pueden confundirse:

1. "Maquinista", "mecánico", "operador de máquinas":

- "Maquinista": construye piezas, herramientas y máquinas de metal mediante el uso de planos de diseño, máquinas herramienta y de mano, e instrumentos de medición precisa.

- "Mecánico": inspecciona, mantiene y repara maquinaria.

- "Operador de máquinas": opera máquinas en fábricas; por ejemplo, una prensa de taladro o una bobinadora.

2. "Persona que hace tareas domésticas", "casero/ama de llaves" / "empleado/a doméstico/a" / "asistenta":

- "Persona que hace tareas domésticas": administra la casa mientras su cónyuge gana el ingreso familiar. También conocido como "madre que se queda en casa", "padre que se queda en casa", "cónyuge que se queda en casa" o "señora de la casa".

- "Casero/ama de llaves" / "empleado/a doméstico/a"/ "asistenta": hace el trabajo de la casa por un salario en residencias privadas (no en su propia casa). Esto no es lo mismo que "servicio de limpieza".

Remítase al capítulo 3, punto 9 (persona que hace tareas

domésticas) para obtener más información. 
Esta página se dejó en blanco de manera intencional. 


\section{Capítulo 5}

\section{Cómo completar la información sobre el tipo de empresa o industria}

\section{Definición}

Tipo de empresa o industria: Tipo de empresa o industria donde la persona fallecida trabajó en su ocupación habitual.

\section{A) Instrucciones}

En el espacio que tiene el certificado de defunción para el tipo de empresa o industria, ingrese el tipo de empresa o industria donde la persona fallecida trabajó la mayor parte de su vida o durante más tiempo. No ingrese nombres de empresas.

1. Siempre ingrese el tipo de empresa o industria. Debe reportarse aunque se desconozca la ocupación habitual de la persona fallecida.

2. Solo use términos que describan claramente el tipo de empresa o industria del lugar donde la persona fallecida estaba empleada.

- Los términos deben indicar tanto una función general como una función específica relacionada con el empleador. Entre los ejemplos de función específica están ganadería, fábrica de autos, tienda de alimentos al por mayor, librería de venta al por menor, construcción de caminos y servicio de reparación de zapatos.

- Las palabras "agricultura", "manufactura", "al por mayor", "al por menor", "construcción" y "servicios de reparación" se refieren a categorías generales de industria, y por lo tanto solo describen funciones amplias o generales. Combinar términos generales con una función específica por lo general proporcionará el mejor nivel de detalle. Vea la tabla 2 para encontrar ejemplos de combinaciones de tipo de empresa o industria y función específica. 
Tabla 2

\begin{tabular}{ll}
\hline \multicolumn{1}{c}{ Industria general } & Empresa o industria con función específica \\
\hline Agricultura & Hacienda ganadera, finca frutícola \\
Manufactura & Fábrica de autos, fábrica de alimentos \\
Venta al por mayor & Venta de alimentos al por mayor, venta de materiales de \\
& plomería al por mayor \\
Venta al por menor & Librería de venta al por menor, mueblería de venta al \\
& por menor \\
Construcción & Construcción de caminos, construcción de edificios \\
Servicios de reparación & Servicio de reparación de zapatos, servicio de reparación \\
& de transmisiones \\
\hline
\end{tabular}

3. Para obtener más información sobre funciones específicas del tipo de empresa o industria, haga este tipo de preguntas:

- Si el informador reporta que la persona fallecida trabajaba en la atención médica, pregunte "¿En qué tipo de lugar, hospital, consultorio médico o centro médico?".

- Si el informador reporta que la persona fallecida trabajaba en el sector automotor, pregunte " ¿Fabricaba, reparaba o vendía autos?”.

- Si el informador reporta que la persona fallecida trabajaba en una empresa de servicios, pregunte “¿Qué tipo de servicios desempeñaba?". Entre los ejemplos podrían estar reparación de refrigeradores, servicio de lavandería y servicio de limpieza.

4. Es importante distinguir entre las empresas manufactureras, mayoristas, minoristas, y de servicios. Si bien una planta manufacturera vende sus productos en grandes cantidades a otros fabricantes, mayoristas y minoristas, repórtela como empresa manufacturera. Use lo siguiente como guía:

- Un establecimiento mayorista compra, en lugar de fabricar, productos en grandes cantidades para revenderlos a los minoristas, los usuarios industriales $\mathrm{u}$ otros mayoristas.

- Un minorista vende principalmente a clientes o usuarios individuales, pero muy rara vez fabrica productos.

- Entre los establecimientos que brindan servicios a personas particulares y a organizaciones se incluyen hoteles, lavanderías, empresas de limpieza, agencias de publicidad y talleres de reparación de autos. 


\section{B) Situaciones especiales}

Los siguientes son puntos importantes para recordar cuando se ingrese el tipo de empresa o industria:

1. Las empresas con frecuencia operan en más de una actividad o industria, a veces en la misma ubicación.

- Ingrese la actividad o industria específica en la que la persona trabajaba, no el nombre de la empresa.

\section{Ejemplo}

Un químico trabajaba en una planta de celulosa operada por Eastman Kodak Company.

Tipo de empresa o industria debe ser "planta de celulosa", no "Eastman Kodak Company" o "fábrica de cámaras".

2. Instituciones gubernamentales.

- Ingrese el nivel de Gobierno; por ejemplo, federal, estatal, de condado o municipal.

- Ingrese la actividad de la institución gubernamental y el nombre de la institución específica, si es responsable de varias actividades.

\section{Ejemplo}

\begin{tabular}{ccc}
\hline Nivel de gobierno & Actividad general & Actividad específica \\
\hline Ciudad & $\begin{array}{c}\text { Departamento de Obras } \\
\text { Públicas }\end{array}$ & $\begin{array}{c}\text { Reparación de calles de } \\
\text { la ciudad } \\
\text { Recolección de desechos de } \\
\text { la ciudad } \\
\text { Eliminación de aguas } \\
\text { residuales de la ciudad }\end{array}$ \\
$\begin{array}{l}\text { La mejor manera de reportar sería reparación de calles de la ciudad, recolección de desechos de la ciudad o eliminación de aguas } \\
\text { residuales de la ciudad. }\end{array}$ &
\end{tabular}

- Ingrese el nombre de la institución de Gobierno solo si su actividad está clara.

\section{Ejemplo}

- Oficina del Censo de los Estados Unidos

- Departamento de bomberos de la ciudad 


\section{Capítulo 5: Cómo completar la información sobre el tipo de empresa o industria}

\section{Actividades económicas en la casa.}

- Algunas personas realizan actividades económicas en su casa. Estas actividades deben reportarse de la misma manera que se reportan las empresas. Entre los ejemplos están un negocio de corte y confección, una biblioteca de préstamo, un taller de construcción de muebles, un negocio de reparación de radios y un consultorio médico.

4. Personas que trabajan en diferentes ubicaciones.

- Algunos trabajadores deben desempeñar sus labores en diferentes ubicaciones, en lugar de en una tienda, fábri$\mathrm{ca} u$ oficina específica. Esto incluye a personas que normalmente trabajan en diferentes ubicaciones en distintos momentos. En esos casos, reporte el tipo de institución o industria en la que trabajaban.

\section{Ejemplo}

\begin{tabular}{ll}
\hline \multicolumn{1}{c}{ Ocupación } & Tipo de institución o industria \\
\hline $\begin{array}{l}\text { Entrevistadores del } \\
\text { Censo. }\end{array}$ & Oficina del Censo de los EE. UU. \\
Pintores de edificios & Construcción \\
Jardineros & Jardinería \\
\hline
\end{tabular}

5. Labores domésticas y otros trabajadores de casas privadas.

- Si se da el nombre de alguien como el nombre del empleador, pregunte si la persona fallecida trabajaba en una empresa o en una casa privada. Por ejemplo, si la persona fallecida era empleada doméstica en la casa privada de Juan Q. Público, la información correcta para ingresar sería "casa privada". Por otro lado, si la persona limpiaba oficinas en una casa privada, como un consultorio médico o un despacho de abogado, la información correcta para ingresar en tipo de empresa o industria sería "consultorio médico" o "despacho de abogado".

Los títulos comunes no son adecuados para algunas industrias. Remítase al apéndice B para ver más ejemplos. 


\section{Capítulo 6}

\section{Situaciones en las que hubo varios trabajos a lo largo de la vida}

\section{Situación: 35 años como soldador y 5 años como guardia nocturno}

Un hombre trabajó durante 35 años como soldador en una fábrica de acero. Antes de jubilarse, trabajó como guardia nocturno durante 5 años.

¿Cuál es su ocupación habitual y el tipo de empresa o industria?

Ocupación habitual: "Soldador"

Tipo de empresa o industria: "Fabricación de acero"

Si bien fue guardia nocturno durante muchos años antes de jubilarse, trabajó como soldador durante más tiempo (35 años). Fabricación de acero es el tipo de industria en el que trabajó como soldador.

\section{Situación: 27 años como minero del carbón y 8 años como conserje después de jubilarse}

Un hombre trabajó 27 años como minero del carbón. Después de jubilarse, trabajó durante ocho años como conserje en una escuela media secundaria.

¿Cuál es su ocupación habitual y tipo de empresa o industria?

Ocupación habitual: "Minero del carbón"

Tipo de empresa o industria: "Minería de carbón"

El trabajo como minero abarcó la mayor parte de sus años laborales; por lo tanto, el trabajo que tuvo durante más tiempo fue el de minero (27 años). La minería de carbón es el tipo específico de industria en la que fue minero.

\section{Situación: 22 años como vendedora en una tienda y 18 años como ama de casa}

Una mujer trabajó 22 años como vendedora en la tienda Macy's. Luego, dejó ese trabajo y se convirtió en ama de casa. Fue ama de casa durante 18 años.

¿Cuál es su ocupación habitual y tipo de empresa o industria?

Ocupación habitual: "Vendedora en una tienda"

Tipo de empresa o industria: "Centro comercial, tienda minorista"

Trabajó como vendedora en una tienda fuera de su casa; solo tendría que ingresar ama de casa si nunca hubiera trabajado fuera de la casa. Por lo tanto, vendedora en una tienda es el trabajo que tuvo durante más tiempo (22 años). Centro comercial, tienda minorista es el tipo específico de empresa en el que fue vendedora. Nótese que el nombre de la empresa, Macy's, no es útil como información para ingresar. 
Esta página se dejó en blanco de manera intencional. 


\section{Capítulo 7}

\section{Lista de verificación: cómo revisar la información que ha ingresado}

Siga esta lista para mejorar la calidad de la información ingresada para ocupación habitual y tipo de empresa o industria de la persona fallecida.

\section{1. ¿Tenía la persona fallecida $\mathbf{1 4}$ años de edad o más?}

Sí: Ingrese la ocupación habitual y el tipo de empresa $o$ industria de la persona fallecida.

No: Ingrese "bebé”, "niño/a" o "estudiante", según corresponda.

\section{2. ¿Estaba jubilada la persona fallecida?}

Sí: Aunque la persona fallecida haya estado jubilada, ingrese la ocupación habitual y el tipo de empresa o industria.

No: Ingrese la ocupación habitual y el tipo de empresa o industria.

\section{3. ¿Estaba la persona fallecida empleada por cuenta propia?}

Sí: Ingrese el tipo de trabajo que desempeñaba, incluidos la profesión o el oficio, para la ocupación habitual. Para tipo de empresa o industria, ingrese la misma ocupación habitual con el término "empleado por cuenta propia".

No: Ingrese la ocupación habitual y el tipo de empresa o industria.

\section{4. ¿Era la persona fallecida una ama de casa que trabaja- ba fuera de su propia casa?}

Sí: Ingrese la ocupación habitual y el correspondiente tipo de empresa o industria de la persona fallecida, si trabajaba fuera de su propia casa.

Ingrese "trabajo doméstico" para la ocupación habitual de la persona fallecida y "casa particular" para el tipo de empresa o industria si la persona fallecida trabajaba por un salario en la casa de otra persona.

No: Ingrese "persona que hace tareas domésticas" para la ocupación habitual de la persona fallecida y "en su propia casa" para el tipo de empresa o industria si la persona fallecida solo trabajaba en su propia casa. 


\section{Capítulo 7: Lista de verificación: cómo revisar la información que ha ingresado}

\section{5. ¿Dejó algún casillero en blanco?}

$\square$ Sí: No deje casilleros en blanco. Siempre ingrese la ocupación habitual y el tipo de empresa o industria. Si la persona fallecida nunca trabajó a lo largo de su vida, ingrese "nunca trabajó" para la ocupación habitual y el tipo de empresa o industria.

$\square$ No: ¡Muy bien! En ambos casilleros, ocupación habitual y tipo de empresa o industria, siempre debe haber una respuesta. 


\section{Apéndice A}

\section{Ejemplos de información ingresada sobre la ocupación que requiere más detalles}

La siguiente lista consiste en ejemplos de ocupaciones que requieren más detalles: en esta lista se incluyen ejemplos de información ingresada que es inadecuada - considerada demasiado general o que requiere más detalles - así como de información ingresada que es adecuada. Las ocupaciones que se reportan de forma inadecuada con más frecuencia aparecen en negrita. Nótese que los ejemplos de ocupaciones considerados adecuados no incluyen todos los títulos aceptables para esa ocupación. Remítase al apéndice $\mathrm{C}$ para obtener información adicional.

\begin{tabular}{ll}
\hline \multicolumn{1}{c}{ Inadecuada } & \multicolumn{1}{c}{ Adecuada } \\
\hline Contabilidad & Contador público autorizado \\
Trabajo de contabilidad & Contador \\
& Operador de máquina contable \\
& Auditor de impuestos \\
& Responsable de contabilidad de acreedores \\
\hline Ajustador & Ajustador de frenos \\
& Ajustador de máquinas \\
& Ajustador de reclamaciones sobre mercancía \\
& Ajustador de seguros \\
\hline Agente & Agente de carga \\
& Agente de seguros \\
& Agente de ventas \\
& Agente publicitario \\
& Agente de compras \\
\hline Analista & Analista de cemento \\
& Analista de alimentos \\
& Analista de presupuesto \\
& Analista de sistemas computacionales \\
& Analista de procedimientos \\
& Analista del aire \\
\hline Corredor & Corredor de bolsa de valores \\
& Corredor de pólizas de seguro \\
& Corredor de bienes raíces \\
& Corredor de cabezas de ganado \\
\hline & \\
\hline & \\
& \\
& \\
& \\
&
\end{tabular}




\section{Apéndice A: Ejemplos de información ingresada sobre la ocupación que requiere más detalles}

\begin{tabular}{|c|c|}
\hline Inadecuada & Adecuada \\
\hline \multirow[t]{7}{*}{ Encargado o cuidador } & Conserje \\
\hline & Guardia \\
\hline & Superintendente del edificio \\
\hline & Jardinero \\
\hline & Jefe de mantenimiento \\
\hline & Recepcionista del edificio \\
\hline & Encargado de los casilleros/armarios \\
\hline \multirow[t]{4}{*}{ Ajustador de reclamaciones } & $\begin{array}{l}\text { Registrador de reclamaciones de compensación } \\
\text { por desempleo }\end{array}$ \\
\hline & Ajustador de pólizas de seguro de autos \\
\hline & Agente de reclamaciones por derecho de paso \\
\hline & Ajustador de reclamaciones sobre mercancía \\
\hline \multirow[t]{3}{*}{ Encargado } & Encargado de inventario \\
\hline & Encargado de envíos \\
\hline & $\begin{array}{l}\text { Encargado de ventas o vendedor (persona que vendía } \\
\text { artículos en una tienda) }\end{array}$ \\
\hline \multirow[t]{4}{*}{ Consultor } & Asesor financiero \\
\hline & Asesor jurídico \\
\hline & Asesor fiscal \\
\hline & Asesor de mercadeo \\
\hline \multirow[t]{3}{*}{ Contratista } & $\begin{array}{l}\text { Contratista de construcción (especifique si hacía trabajo } \\
\text { manual o administrativo) }\end{array}$ \\
\hline & Contratista de gerencia \\
\hline & $\begin{array}{l}\text { Contratista de pintura (especifique si hacía trabajo } \\
\text { administrativo, de gerencia o manual) }\end{array}$ \\
\hline \multirow[t]{5}{*}{ Consejero } & Consejero educativo \\
\hline & Consejero de personal \\
\hline & Consejero de rehabilitación \\
\hline & Consejero de orientación vocacional \\
\hline & Consejero matrimonial \\
\hline \multirow[t]{6}{*}{ Procesamiento de datos } & Programador de computadoras \\
\hline & Mecanógrafo de datos \\
\hline & Operador de perforadora de tarjetas \\
\hline & Operador de computadora \\
\hline & Encargado de codificación \\
\hline & Operador de convertidor de cinta a tarjeta \\
\hline \multirow[t]{5}{*}{ Médico } & Optómetra \\
\hline & Dentista \\
\hline & Veterinario \\
\hline & Siquiatra \\
\hline & Quiropráctico \\
\hline
\end{tabular}




\section{Apéndice A: Ejemplos de información ingresada sobre la ocupación que requiere más detalles}

\begin{tabular}{|c|c|}
\hline Inadecuada & Adecuada \\
\hline \multirow[t]{6}{*}{ Ingeniero } & Ingeniero civil \\
\hline & Ingeniero de locomotoras \\
\hline & Ingeniero mecánico \\
\hline & Ingeniero aeronáutico \\
\hline & Ingeniero eléctrico \\
\hline & Ingeniero de construcción \\
\hline \multirow[t]{3}{*}{ Operador de equipos } & Operador de máquina niveladora \\
\hline & Operador de excavadora (bulldozer) \\
\hline & Operador de zanjadora \\
\hline \multirow[t]{11}{*}{ Obrero de fábrica } & $\begin{array}{l}\text { Ensamblador (agregar el nombre del producto } \\
\text { que ensamblaba) }\end{array}$ \\
\hline & Operador de máquina \\
\hline & Operador de forja de fundición \\
\hline & Operador/supervisor suplente \\
\hline & Operador de torno revolver \\
\hline & Hilandero \\
\hline & Técnico de telar \\
\hline & Tejedor, cosedor \\
\hline & Operador de punzonadora \\
\hline & Rociador de pintura \\
\hline & Remachador \\
\hline \multirow[t]{8}{*}{ Agricultor } & $\begin{array}{l}\text { Agricultor o agregado (persona responsable de la } \\
\text { operación de una hacienda) }\end{array}$ \\
\hline & $\begin{array}{l}\text { Jornalero (persona que hacía el trabajo agrícola general } \\
\text { por un salario; podría ser un familiar) }\end{array}$ \\
\hline & $\begin{array}{l}\text { Ayudante de finca (pariente que vivía en la casa y } \\
\text { trabajaba en la hacienda familiar sin recibir un salario) }\end{array}$ \\
\hline & $\begin{array}{l}\text { Administrador de hacienda (persona que fue contratada } \\
\text { para administrar una hacienda de otra persona) }\end{array}$ \\
\hline & $\begin{array}{l}\text { Trabajador de servicios agrícolas (trabajador que iba } \\
\text { de finca en finca para cosechar, recoger, o hacer } \\
\text { operaciones similares, por contrato, generalmente con } \\
\text { sus propios equipos) }\end{array}$ \\
\hline & $\begin{array}{l}\text { Supervisor de hacienda (persona contratada para } \\
\text { supervisar a un grupo de jornaleros) }\end{array}$ \\
\hline & $\begin{array}{l}\text { Recogedor de fruta (persona contratada para hacer una } \\
\text { tarea específica) }\end{array}$ \\
\hline & $\begin{array}{l}\text { Jornalero ambulante (persona que se trasladaba de un lugar } \\
\text { a otro para ayudar a sembrar y cosechar los cultivos) }\end{array}$ \\
\hline
\end{tabular}




\section{Apéndice A: Ejemplos de información ingresada sobre la ocupación que requiere más detalles}

\begin{tabular}{|c|c|}
\hline Inadecuada & Adecuada \\
\hline Bombero & $\begin{array}{l}\text { Bombero que combatía incendios forestales } \\
\text { Bombero de locomotora } \\
\text { Bombero de ciudad (departamento de bomberos } \\
\text { de la ciudad) } \\
\text { Operador de altos hornos } \\
\text { Operador de calderas } \\
\text { Contramaestre de incendio }\end{array}$ \\
\hline $\begin{array}{l}\text { Capataz } \\
\text { (se debe especificar el oficio o la actividad) }\end{array}$ & $\begin{array}{l}\text { Capataz carpintero } \\
\text { Capataz de camioneros } \\
\text { Capataz de hacienda }\end{array}$ \\
\hline $\begin{array}{l}\text { Operador de maquinaria pesada } \\
\text { (se debe especificar el tipo de maquinaria) }\end{array}$ & $\begin{array}{l}\text { Operador de pala mecánica } \\
\text { Operador de grúa Derrick } \\
\text { Operador de grúa monorriel } \\
\text { Operador de dragalina } \\
\text { Operador de camiones o tractores industriales }\end{array}$ \\
\hline Ayudante & $\begin{array}{l}\text { Ayudante de panadero } \\
\text { Ayudante de carpintero } \\
\text { Ayudante de conserje }\end{array}$ \\
\hline Investigador & $\begin{array}{l}\text { Investigador de reclamaciones de pólizas de seguro } \\
\text { Investigador de declaraciones de impuestos a la renta } \\
\text { Examinador financiero } \\
\text { Investigador de beneficiarios del Seguro Social }\end{array}$ \\
\hline Obrero & $\begin{array}{l}\text { Obrero de la construcción } \\
\text { Trabajador de lavandería } \\
\text { Obrero de almacén } \\
\text { Obrero de la industria petrolera }\end{array}$ \\
\hline Trabajador de trazado o diagramación & $\begin{array}{l}\text { Diseñador de patrones } \\
\text { Planchista metalúrgico } \\
\text { Tipógrafo } \\
\text { Artista comercial } \\
\text { Obrero metalúrgico de estructuras } \\
\text { Delineante } \\
\text { Artesano del cobre }\end{array}$ \\
\hline Trabajador de mantenimiento & $\begin{array}{l}\text { Jefe de mantenimiento } \\
\text { Conserje } \\
\text { Carpintero } \\
\text { Electricista }\end{array}$ \\
\hline
\end{tabular}




\section{Apéndice A: Ejemplos de información ingresada sobre la ocupación que requiere más detalles}

\begin{tabular}{|c|c|}
\hline Inadecuada & Adecuada \\
\hline \multirow[t]{4}{*}{ Gerente } & Gerente de cocina \\
\hline & Gerente de oficina \\
\hline & Gerente de personal \\
\hline & Gerente de almacén \\
\hline \multirow[t]{6}{*}{ Mecánico } & Mecánico de autos \\
\hline & Mecánico de transmisiones de autos \\
\hline & Mecánico de motores de aviones \\
\hline & Mecánico de ascensores \\
\hline & Técnico mecánico de fotocopiadoras \\
\hline & Mecánico de frenos de autos \\
\hline \multirow[t]{6}{*}{ Personal de enfermería } & Enfermera o enfermero graduado (registered nurse) \\
\hline & Enfermera partera \\
\hline & Enfermera o enfermero práctico (practical nurse) \\
\hline & Asistente de enfermería \\
\hline & Enfermera estudiante \\
\hline & $\begin{array}{l}\text { Enfermera o enfermero con especialidad en práctica } \\
\text { avanzada (nurse practitioner) }\end{array}$ \\
\hline \multirow[t]{7}{*}{ Empleado de oficina } & Mecanógrafo \\
\hline & Secretario \\
\hline & Recepcionista \\
\hline & Operador de computadora \\
\hline & Encargado del archivo \\
\hline & Contador \\
\hline & Asistente del médico \\
\hline \multirow[t]{3}{*}{ Especialista de programa } & Planificador de programa \\
\hline & Supervisor de sistemas de procesamiento de datos \\
\hline & Coordinador de flujo de metal \\
\hline \multirow[t]{4}{*}{ Programador } & Programador de computadoras \\
\hline & Programador de datos electrónicos \\
\hline & Director de programación de radio o televisión \\
\hline & Planificador de producción \\
\hline $\begin{array}{l}\text { Trabajador de empresa ganadera } \\
\text { (ver Agricultor) }\end{array}$ & $\begin{array}{l}\text { Ganadero } \\
\text { Peón ganadero }\end{array}$ \\
\hline $\begin{array}{l}\text { Investigación (se debe especificar el } \\
\text { campo de investigación; se debe incluir } \\
\text { "asociado" o "auxiliar" si forma parte del } \\
\text { título) }\end{array}$ & $\begin{array}{l}\text { Físico investigador } \\
\text { Químico investigador } \\
\text { Matemático investigador } \\
\text { Biólogo investigador } \\
\text { Químico investigador asociado } \\
\text { Físico investigador auxiliar } \\
\text { Geólogo investigador asociado }\end{array}$ \\
\hline
\end{tabular}




\section{Apéndice A: Ejemplos de información ingresada sobre la ocupación que requiere más detalles}

\begin{tabular}{|c|c|}
\hline Inadecuada & Adecuada \\
\hline Trabajador de ventas & $\begin{array}{l}\text { Venta de publicidad } \\
\text { Venta de pólizas de seguro } \\
\text { Venta de bonos } \\
\text { Venta de artículos entregados por choferes de vehículos } \\
\text { Venta de diarios/periódicos }\end{array}$ \\
\hline Científicos & $\begin{array}{l}\text { Politólogo } \\
\text { Físico } \\
\text { Sociólogo } \\
\text { Epidemiólogo } \\
\text { Oceanógrafo } \\
\text { Científico de suelos }\end{array}$ \\
\hline Departamento de envíos & $\begin{array}{l}\text { Encargado de envíos y recepción } \\
\text { Encargado de contenedores } \\
\text { Encargado de tomar pedidos } \\
\text { Mecanógrafo } \\
\text { Encargado de envolver los envíos }\end{array}$ \\
\hline Supervisor & $\begin{array}{l}\text { Supervisor de mecanografía } \\
\text { Supervisor de contabilidad } \\
\text { Delegado de taller } \\
\text { Supervisor de cocina } \\
\text { Supervisor de cuentas } \\
\text { Supervisor de corte y confección } \\
\text { Director de ventas } \\
\text { Supervisor de rutas } \\
\text { Supervisor de recreación } \\
\text { Supervisor de servicios }\end{array}$ \\
\hline $\begin{array}{l}\text { Maestro (la ocupación de maestro debe } \\
\text { reportarse con el nivel que se enseñaba; } \\
\text { se debe incluir la materia para quienes } \\
\text { enseñaban a un nivel superior a la escuela } \\
\text { primaria) }\end{array}$ & $\begin{array}{l}\text { Maestro de prescolar } \\
\text { Maestro de jardín de infantes (kínder) } \\
\text { Maestro de escuela primaria } \\
\text { Profesor de inglés en escuela secundaria superior } \\
\text { Profesor universitario (Matemática) }\end{array}$ \\
\hline Técnico & $\begin{array}{l}\text { Técnico de laboratorio médico } \\
\text { Técnico de laboratorio dental } \\
\text { Técnico de radiografías }\end{array}$ \\
\hline Probador & $\begin{array}{l}\text { Probador de cemento } \\
\text { Probador de instrumentos } \\
\text { Probador de motores } \\
\text { Probador de baterías }\end{array}$ \\
\hline $\begin{array}{l}\text { Trabaja en el depósito, la oficina, etc. } \\
\text { (No es suficiente con incluir el nombre } \\
\text { del departamento o el lugar de trabajo) }\end{array}$ & $\begin{array}{l}\text { Encargado de envíos } \\
\text { Encargado del archivo } \\
\text { Cargador de camiones }\end{array}$ \\
\hline
\end{tabular}




\section{Ejemplos de información ingresada sobre la industria que requiere más especificidad}

Los siguientes son ejemplos de industrias que requieren tener un cuidado especial al reportar. En este listado se incluyen ejemplos de información reportada que se considera inadecuada, así como de información correcta o adecuada. Nótese que los ejemplos adecuados de industrias no incluyen todos los títulos aceptables. Las industrias que se reportan de forma inadecuada con más frecuencia aparecen en negrita. Remítase al apéndice $\mathrm{C}$ para obtener información adicional.

\begin{tabular}{ll}
\hline \multicolumn{1}{c}{ Inadecuada } & \multicolumn{1}{c}{ Adecuada } \\
\hline Agencia & Agencia de cobro de deudas \\
& Agencia publicitaria \\
& Agencia inmobiliaria \\
& Agencia de empleo \\
& Agencia de viajes \\
& Agencia de seguros \\
\hline Componentes de aviones, piezas de aviones & Fábrica de piezas de motores de aviones \\
& Fabricación de hélices \\
& Fábrica de instrumentos electrónicos \\
& Venta mayorista de piezas de aviones \\
\hline Componentes de autos & Fabricación de embragues (cloches) de autos \\
Piezas de autos & Venta mayorista de accesorios de autos \\
& Fabricación de gomas de autos \\
& Venta minorista e instalación de silenciadores (mofles) \\
& Fábrica de baterías \\
\hline Panadería & Fábrica de pan (hacen pan y venden a mayoristas, \\
& minoristas y restaurantes) \\
& Panadería mayorista (compra al fabricante y vende a las \\
tiendas de alimentos y los restaurantes, etc.) \\
Panadería minorista (vende solo en su establecimiento a \\
personas particulares) \\
\hline Fábrica de cajas & Fábrica de cajas de cartón \\
& Fábrica de cajas de madera \\
& Fábrica de cajas de metal \\
\hline & Departamento de obras públicas de la ciudad \\
& Departamento de salud de la ciudad \\
& Sistema educativo municipal \\
\hline & Club de golf \\
& Club fraternal \\
& Club nocturno \\
& Club residencial \\
\hline & \\
& \\
& \\
&
\end{tabular}




\section{Apéndice B: Ejemplos de información ingresada sobre la industria que requiere más especificidad}

\begin{tabular}{|c|c|}
\hline Inadecuada & Adecuada \\
\hline \multirow[t]{3}{*}{ Empresa de carbón } & Mina de carbón \\
\hline & Venta mayorista de carbón \\
\hline & Venta minorista de carbón \\
\hline \multirow[t]{2}{*}{ Condado o gobierno del condado } & Departamento de recreación del condado \\
\hline & Junta de educación del condado \\
\hline \multirow[t]{2}{*}{ Empresa de crédito } & Empresa de calificación de crédito \\
\hline & Empresa de préstamos \\
\hline \multirow[t]{5}{*}{ Lácteos } & Vaquería \\
\hline & Tienda de venta de productos lácteos \\
\hline & Venta mayorista de productos lácteos \\
\hline & Venta minorista de productos lácteos \\
\hline & Fabricación de productos lácteos \\
\hline \multirow[t]{4}{*}{ Casa de descuentos, tienda de descuentos } & Farmacia de venta minorista \\
\hline & Venta minorista de electrodomésticos \\
\hline & Venta minorista de mercancía general \\
\hline & Venta minorista de ropa \\
\hline \multirow[t]{4}{*}{ Fabricación de piezas eléctricas } & Fábrica de tubos electrónicos \\
\hline & Fabricación de memorias de núcleo \\
\hline & Fábrica de transistores \\
\hline & Fabricación de lectores de cintas \\
\hline \multirow[t]{4}{*}{ Empresa de ingeniería } & Consultores de ingeniería civil \\
\hline & Contratistas generales \\
\hline & Venta mayorista de equipos de audición \\
\hline & Fábrica de maquinaria de construcción \\
\hline \multirow[t]{4}{*}{ Empresa de envío de paquetes y mercancías } & Envío de mercancía por camión \\
\hline & Agencia de envío de mercancía por tren \\
\hline & Alquiler de vagones de tren (Union Tank Car Co., etc.) \\
\hline & Servicio de vehículos blindados \\
\hline \multirow[t]{7}{*}{ Fábrica, molino o planta } & Fábrica laminadora de acero \\
\hline & Fábrica de herramientas \\
\hline & Fábrica de aviones \\
\hline & Molino de harina \\
\hline & Fábrica de medias/calcetines \\
\hline & Imprenta comercial \\
\hline & Fábrica de telas de algodón \\
\hline \multirow[t]{5}{*}{ Granja } & Hacienda ganadera \\
\hline & Finca de verduras/hortalizas/frutas \\
\hline & Granja avícola \\
\hline & Hacienda ganadera y de cultivo de trigo \\
\hline & Criadero de peces \\
\hline
\end{tabular}




\section{Apéndice B: Ejemplos de información ingresada sobre la industria que requiere más especificidad}

\begin{tabular}{|c|c|}
\hline Inadecuada & Adecuada \\
\hline \multirow[t]{3}{*}{ Fundición } & Fundición de hierro \\
\hline & Fundición de latón \\
\hline & Fundición de aluminio \\
\hline \multirow[t]{3}{*}{ Empresa de transporte de carga } & Envío de mercancía por camión \\
\hline & Envío de mercancía por avión \\
\hline & $\begin{array}{l}\text { Envío de mercancía por tren Transporte acuático } \\
\text { (marítimo-fluvial) }\end{array}$ \\
\hline \multirow[t]{4}{*}{ Atención médica } & Hospital \\
\hline & Consultorio médico \\
\hline & Centro médico \\
\hline & Atención privada \\
\hline \multirow[t]{3}{*}{ Lavado de ropa } & $\begin{array}{l}\text { Lavandería en su propia casa (para una persona que } \\
\text { lavaba ropa en su propia casa a cambio de un pago) }\end{array}$ \\
\hline & $\begin{array}{l}\text { Lavado de ropa para una familia particular (para una } \\
\text { persona que trabajaba en la casa de una familia } \\
\text { particular) }\end{array}$ \\
\hline & $\begin{array}{l}\text { Lavandería comercial (para una persona que trabajaba en } \\
\text { una lavandería de vapor, lavandería de lavado a mano o } \\
\text { establecimiento similar) }\end{array}$ \\
\hline \multirow[t]{5}{*}{ Empresa maderera } & Aserradero \\
\hline & Venta minorista de madera \\
\hline & Taller de cepillado \\
\hline & Campamento forestal \\
\hline & Venta mayorista de madera \\
\hline \multirow[t]{3}{*}{$\begin{array}{l}\text { Agente de fabricante (se debe especificar el } \\
\text { producto que se vende) }\end{array}$} & $\begin{array}{l}\text { Representante de fabricante de joyería } \\
\text { Representante de productor de madera }\end{array}$ \\
\hline & Representante de fabricante de electrodomésticos \\
\hline & Representante de fabricante de productos químicos \\
\hline \multirow[t]{8}{*}{ Mina } & Mina de carbón \\
\hline & Mina de oro \\
\hline & Mina de bauxita \\
\hline & Mina de hierro \\
\hline & Mina de cobre \\
\hline & Mina de plomo \\
\hline & Cantera de mármol \\
\hline & Cantera de arena y grava \\
\hline \multirow[t]{3}{*}{ Fábrica de nailon } & $\begin{array}{l}\text { Fábrica de nailon químico (donde los productos químicos } \\
\text { se convierten en fibras) }\end{array}$ \\
\hline & $\begin{array}{l}\text { Fábrica de telas de nailon (donde las fibras se convierten } \\
\text { en hilo o se tejen para hacer telas) }\end{array}$ \\
\hline & $\begin{array}{l}\text { Fábrica de medias de nailon de mujer (donde el hilo se } \\
\text { convierte en medias) }\end{array}$ \\
\hline
\end{tabular}




\section{Apéndice B: Ejemplos de información ingresada sobre la industria que requiere más especificidad}

\begin{tabular}{|c|c|}
\hline Inadecuada & Adecuada \\
\hline \multirow[t]{3}{*}{ Consultorio/oficina } & Consultorio dental \\
\hline & Consultorio médico \\
\hline & Oficina de seguros \\
\hline \multirow[t]{6}{*}{ Industria petrolera } & Perforación en campos petroleros \\
\hline & Refinería de petróleo \\
\hline & Gasolinera minorista \\
\hline & Oleoducto \\
\hline & Distribuidor mayorista de petróleo \\
\hline & Venta minorista de combustible de petróleo \\
\hline \multirow[t]{3}{*}{ Planta de empaque } & Planta de empaque de carne \\
\hline & Planta de enlatado de fruta \\
\hline & $\begin{array}{l}\text { Almacén de empaque de fruta (empaque y envío de fruta } \\
\text { al por mayor) }\end{array}$ \\
\hline \multirow[t]{4}{*}{ Oleoductos y gasoductos } & Gasoducto \\
\hline & Tuberías de gasolina \\
\hline & Oleoducto \\
\hline & Construcción de oleoductos y gasoductos \\
\hline \multirow[t]{2}{*}{ Fábrica de plástico } & $\begin{array}{l}\text { Fábrica de productos de plástico (donde se hacen } \\
\text { materiales plásticos) }\end{array}$ \\
\hline & $\begin{array}{l}\text { Planta de productos de plástico (donde se fabrican } \\
\text { artículos de materiales plásticos) }\end{array}$ \\
\hline \multirow{4}{*}{$\begin{array}{l}\text { Empresa de servicios públicos (se deben } \\
\text { especificar todos los servicios, como gas y } \\
\text { electricidad, o electricidad y agua) }\end{array}$} & Servicio de luz y electricidad \\
\hline & Servicio de gas \\
\hline & Servicio telefónico \\
\hline & Servicio de suministro de agua \\
\hline \multirow[t]{3}{*}{ Ferrocarril } & Fábrica de vagones de tren \\
\hline & Taller de reparación de trenes con motores diésel \\
\hline & Fábrica de locomotoras \\
\hline \multirow[t]{7}{*}{ Taller de reparación } & Taller de reparación de zapatos (zapatería) \\
\hline & Taller de reparación de televisores \\
\hline & Taller de reparación de radios \\
\hline & Cerrajería \\
\hline & Taller de soldaduras \\
\hline & Taller mecánico (para autos) \\
\hline & Taller de reparación de máquinas \\
\hline
\end{tabular}




\section{Apéndice B: Ejemplos de información ingresada sobre la industria que requiere más especificidad}

\begin{tabular}{|c|c|}
\hline Inadecuada & Adecuada \\
\hline Investigación & $\begin{array}{l}\text { Vestidos de tela que no se arruga (producto de la empresa } \\
\text { para la que se hizo la investigación) } \\
\text { Universidad de Brandeis (nombre de la universidad para la } \\
\text { que se hizo la investigación) } \\
\text { Hospital St. Elizabeth (nombre del hospital para el que se } \\
\text { hizo la investigación médica) } \\
\text { Investigación comercial (si la investigación es el principal } \\
\text { servicio de la empresa) } \\
\text { Brookings Institution (nombre de la organización sin } \\
\text { fines de lucro) }\end{array}$ \\
\hline $\begin{array}{l}\text { Escuela (se deben distinguir las escuelas } \\
\text { públicas y privadas, incluidos los colegios } \\
\text { religiosos, y se debe identificar el nivel } \\
\text { más alto de instrucción, como universidad } \\
\text { de carreras cortas o escuela secundaria } \\
\text { superior) }\end{array}$ & $\begin{array}{l}\text { Escuela primaria de la ciudad } \\
\text { Kínder (jardín de infantes) privado } \\
\text { Universidad privada }\end{array}$ \\
\hline Taller de costura/sastrería & $\begin{array}{l}\text { Tintorería (brinda servicio de lavado y planchado) } \\
\text { Sastrería (donde se hace ropa a la medida) } \\
\text { Tienda de alquiler de ropa para hombres }\end{array}$ \\
\hline Terminal & $\begin{array}{l}\text { Terminal de autobuses } \\
\text { Terminal de trenes } \\
\text { Terminal de embarcaciones } \\
\text { Terminal de aeropuerto }\end{array}$ \\
\hline Fábrica textil & $\begin{array}{l}\text { Fábrica de telas de algodón } \\
\text { Fábrica de telas de lana } \\
\text { Fábrica de hilo de algodón } \\
\text { Fábrica de hilo de nailon }\end{array}$ \\
\hline Empresa de transporte & $\begin{array}{l}\text { Transporte por camión } \\
\text { Mudanzas y almacenamiento } \\
\text { Transporte acuático (marítimo-fluvial) } \\
\text { Transporte aéreo Aerolínea } \\
\text { Servicio de taxi } \\
\text { Metro (subterráneo) } \\
\text { Tren elevado } \\
\text { Vía del ferrocarril } \\
\text { Servicio de carga de vagones }\end{array}$ \\
\hline Empresa de agua & $\begin{array}{l}\text { Suministro de agua } \\
\text { Sistemas de irrigación } \\
\text { Planta de filtración/tratamiento de agua }\end{array}$ \\
\hline Pozo & $\begin{array}{l}\text { Perforación en campos petroleros } \\
\text { Perforación de pozos petroleros } \\
\text { Perforación de pozos de sal } \\
\text { Perforación de pozos de agua }\end{array}$ \\
\hline
\end{tabular}


Esta página se dejó en blanco de manera intencional. 


\section{Apéndice \\ Ejemplos de información ingresada de forma aceptable sobre la ocupación y la industria}

Estos son ejemplos de información ingresada de forma aceptable sobre la ocupación y el tipo de empresa o industria correspondiente; la Oficina del Censo de los Estados Unidos ha elaborado la lista. La lista se presenta como guía para reportar de forma adecuada.

\begin{tabular}{ll}
\hline \multicolumn{1}{c}{ Ocupación } & Tipo de empresa, oficio o industria \\
\hline Abogado & Abogado empleado por cuenta propia \\
Abogado & Sociedad para Asistencia Legal \\
Auditor & Asociación de ahorro y préstamo \\
Contador & Droguería \\
Camarógrafo & Estación de televisión \\
Carpintero & Construcción de edificaciones \\
Instalador de alfombras & Venta minorista e instalación de alfombras \\
Cajero/a & Banco \\
Capellán & Prisión estatal \\
Conductor & Departamento de bomberos de la ciudad \\
Chofer & Empresa de taxis \\
Químico & Fábrica de película plástica \\
Programador de computadoras & Empresa de seguros de vida \\
Chofer de entregas & Panadería de venta mayorista \\
Costurera/modista & Tienda de corte y confección \\
Electricista & Empresa de luz y electricidad \\
Examinador de campo & Administración de Salud de Veteranos \\
Ingeniero de vuelo & (Gobierno de los EE. UU.) \\
& Empresa de aeronáutica (fabricación, venta \\
Geólogo & minorista o venta mayorista) \\
Agente de seguros & Exploración petrolera \\
Conserje & Empresa de seguros de vida \\
Juez & Edificio de oficinas de la ciudad \\
Mecánico de autos & Tribunales del condado \\
Médico & Taller de reparación de motores \\
Minero & Departamento de salud (Gobierno estatal) \\
Operador de motores (jubilado) & Mina de carbón \\
Dueño (embalsamador y gerente) & Sistema de transporte urbano \\
Dueño/gerente & Funeraria \\
Analista de empresa petrolera & Tienda minorista de alimentos \\
Piloto & Refinería de petróleo \\
Gerente de planta & Aerolínea comercial \\
& Refine petróleo \\
\hline &
\end{tabular}




\section{Apéndice C: Ejemplos de información ingresada de forma aceptable sobre la ocupacióny la industria}

\begin{tabular}{|c|c|}
\hline Ocupación & Tipo de empresa, oficio o industria \\
\hline Presidente & Escuela de Administración de Empresas \\
\hline Operador de imprenta (aprendiz) & Imprenta \\
\hline Estimador de costos de producción & $\begin{array}{l}\text { Taller mecánico de hojalatería y pintura } \\
\text { (para autos) }\end{array}$ \\
\hline Profesor (de inglés) & Universidad \\
\hline Trabajador de cantera & Cantera de mármol \\
\hline Operador de radio & Estación de radio universitaria \\
\hline Profesional en enfermería & Hospital \\
\hline Senador & Congreso de los Estados Unidos \\
\hline Diseñador de zapatos & Fábrica de zapatos de cuero \\
\hline Bombero que trabaja en la estación & Fábrica de acero \\
\hline Estudiante & Universidad de carreras cortas \\
\hline Supervisor (tejidos) & Fábrica de telas de algodón \\
\hline Supervisor (oficina) & Empresa de seguros de salud y contra accidentes \\
\hline Camionero (teamster) & Campamento forestal \\
\hline Trabajador maderero & Explotación forestal \\
\hline Probador de gomas de auto & Fabricación de gomas de auto \\
\hline Operador de telar & Fábrica de telas de algodón \\
\hline
\end{tabular}




\section{Apéndice D}

\section{El Sistema de Registro de Estadísticas Vitales en los Estados Unidos}

El registro de nacimientos, defunciones, muertes fetales y otros eventos ${ }^{3}$ vitales es una función estatal y local en los Estados Unidos. El código civil de cada estado contempla un sistema de registro continuo, permanente y obligatorio de estadísticas vitales. Cada sistema depende del esfuerzo consciente de médicos, personal hospitalario, directores funerales, funcionarios forenses y médicos forenses para preparar o certificar la información necesaria para completar los registros originales. Para observar una representación gráfica del Sistema de Registro de Estadísticas Vitales en los Estados Unidos, vea la figura 1.

La mayoría de los estados están divididos geográficamente en distritos o unidades de registro para facilitar la recolección de registros vitales. Un distrito puede ser un sector, un pueblo, un municipio, una ciudad, un condado u otra área geográfica o una combinación de dos o más de estas áreas. En algunos estados, sin embargo, la ley establece que los registros de nacimientos, defunciones y muertes fetales deben enviarse directamente desde la fuente de registro (hospital, médico, director funeral) a la oficina estatal de estadísticas vitales. En este sistema, el personal de la oficina estatal asume las funciones que normalmente desempeña un funcionario de registro local.

En los estados con un sistema de registro local, el funcionario de registro local recolecta los registros de eventos que ocurren en su área y los transmite a la oficina estatal de estadísticas vitales. El funcionario de registro local debe asegurarse de que se ingrese un certificado completo para cada evento que ocurra en ese distrito. La oficina estatal de estadísticas vitales inspecciona cada registro con respecto a la prontitud con la que fue ingresado, su exhaustividad y la exactitud de la información; consulta sobre la información que falta o que es incongruente; numera los registros; prepara índices; procesa los registros; y guarda los documentos para conservarlos de forma permanente.

La información estadística de los registros se tabula para que la puedan usar los departamentos de salud estatales y locales, otras agencias gubernamentales y diversas organizaciones privadas y de trabajo voluntario. Los datos se usan para evaluar problemas de salud y planificar programas y servicios para el público. El Centro Nacional de Estadísticas de Salud (NCHS) de los Centros para el Control y la Prevención de Enfermedades tiene la autoridad de administrar las estadísticas vitales a nivel nacional. Los archivos de datos provenientes de registros individuales ingresados en oficinas estatales o, en algunos casos, las copias de los registros individuales se transmiten al NCHS.

Con estos datos se preparan informes estadísticos mensuales, anuales y especiales para los Estados Unidos en general y para las partes constitutivas-ciudades, condados, estados y regiones-por características como sexo, raza y causa de muerte. Las estadísticas son esenciales en los campos de bienestar social, salud pública y demografía. También se usan para diversos propósitos administrativos, tanto en el sector privado como en el sector público. El NCHS sirve como punto focal y ejerce su liderazgo para establecer prácticas uniformes por medio de leyes modelo, formularios estándar para certificados, manuales y otros materiales de instrucción, a fin de mejorar de manera continua el Sistema de Estadísticas Vitales en los Estados Unidos.

\footnotetext{
${ }^{3}$ En la definición de eventos vitales se incluyen nacimientos de bebés vivos, defunciones, muertes fetales, matrimonios, divorcios y terminaciones inducidas de embarazos, junto con todos los cambios en el estado civil que podrían ocurrir durante la vida de una persona.
} 


\section{Apéndice D: El Sistema Nacional de Registro de Estadisticas Vitales en los Estados Unidos}

\section{Cómo usar los datos sobre muertes para las acciones de salud pública}

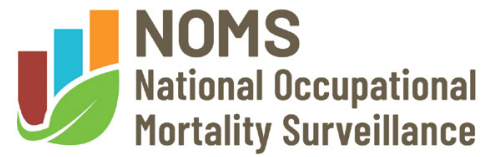

Por medio del Programa Nacional de Vigilancia de Mortalidad Ocupacional (NOMS), el Instituto Nacional para la Seguridad y Salud Ocupacional (NIOSH) usa los datos sobre defunciones para analizar patrones de mortalidad asociados a la ocupación habitual e industria que se reportaron en los certificados de defunción (www.cdc.gov/niosh/topics/noms/). Por ejemplo, el vínculo entre el cáncer de pulmón y la exposición al asbesto en trabajos como la construcción de barcos y edificaciones se descubrió al analizar los datos de certificados de defunción. Desde 1980, NIOSH, junto con el NCHS y el Instituto Nacional del Cáncer (NCI), han recolectado y revisado información-con fines de vigilancia y prevención de salud pública—en certificados de defunción de los Estados Unidos que el NCHS o los estados habían desprovisto de datos identificatorios. Como una de las pocas fuentes de datos representativos sobre las enfermedades crónicas, estos datos se usan para analizar tendencias e identificar riesgos potenciales de mortalidad por enfermedades agudas y crónicas en grupos industriales y ocupacionales.

Las declaraciones de datos sobre la ocupación a lo largo de la vida y la industria que se incluyen en los certificados de defunción pueden brindar información para establecer prioridades e identificar entornos en los lugares de trabajo que estén asociados a un mayor o menor riesgo de enfermarse o lesionarse. NIOSH y otros investigadores han usado los datos en análisis para ampliar los conocimientos sobre resultados de salud relacionados con la ocupación, que van desde la hepatitis hasta la silicosis sistémica relacionada con la sílice. La información que se genera se usa para informar a los funcionarios de salud pública sobre los riesgos de mortalidad, por industria y ocupación, y para identificar áreas de riesgo relacionadas con el trabajo.

Debido a la confiabilidad de los datos de este sistema de vigilancia amplio y representativo-basado en la población-los hallazgos que se basan en esta información han sido usados en los Estados Unidos para respaldar las recomendaciones de salud y seguridad, fortalecer las acciones de prevención, y mejorar la educación de salud pública, los tratamientos médicos y las pruebas de detección. Los datos sobre defunciones con frecuencia se usan para estudiar las enfermedades raras, los trabajadores de razas y poblaciones étnicas minoritarias, y los lugares de trabajo donde no se mantienen registros de los trabajadores.

NIOSH tiene a su cargo la realización de vigilancia de peligros y salud ocupacionales, a fin de identificar tendencias y ayudar a establecer prioridades de investigación y actividades de prevención. Desde los años ochenta, NIOSH ha colaborado con el NCHS, el NCI, la Oficina del Censo de los EE. UU. y otras agencias del Gobierno federal y departamentos de salud estatales, a fin de registrar y codificar la ocupación habitual y el tipo de empresa o industria en los certificados de defunción, con el propósito de hacer la vigilancia de enfermedades, lesiones y exposiciones ocupacionales. Para obtener información sobre los sistemas de clasificación usados para codificar el texto relativo a la industria y la ocupación que registran los directores funerales y su personal, vea la página web del Panorama general sobre industria y ocupación de la Oficina del Censo de los EE. UU.: www.census.gov/topics/employment/industry-occupation/guidance/ indexes.html. 


\section{Apéndice D: El Sistema Nacional de Registro de Estadisticas Vitales en los}

Estados Unidos
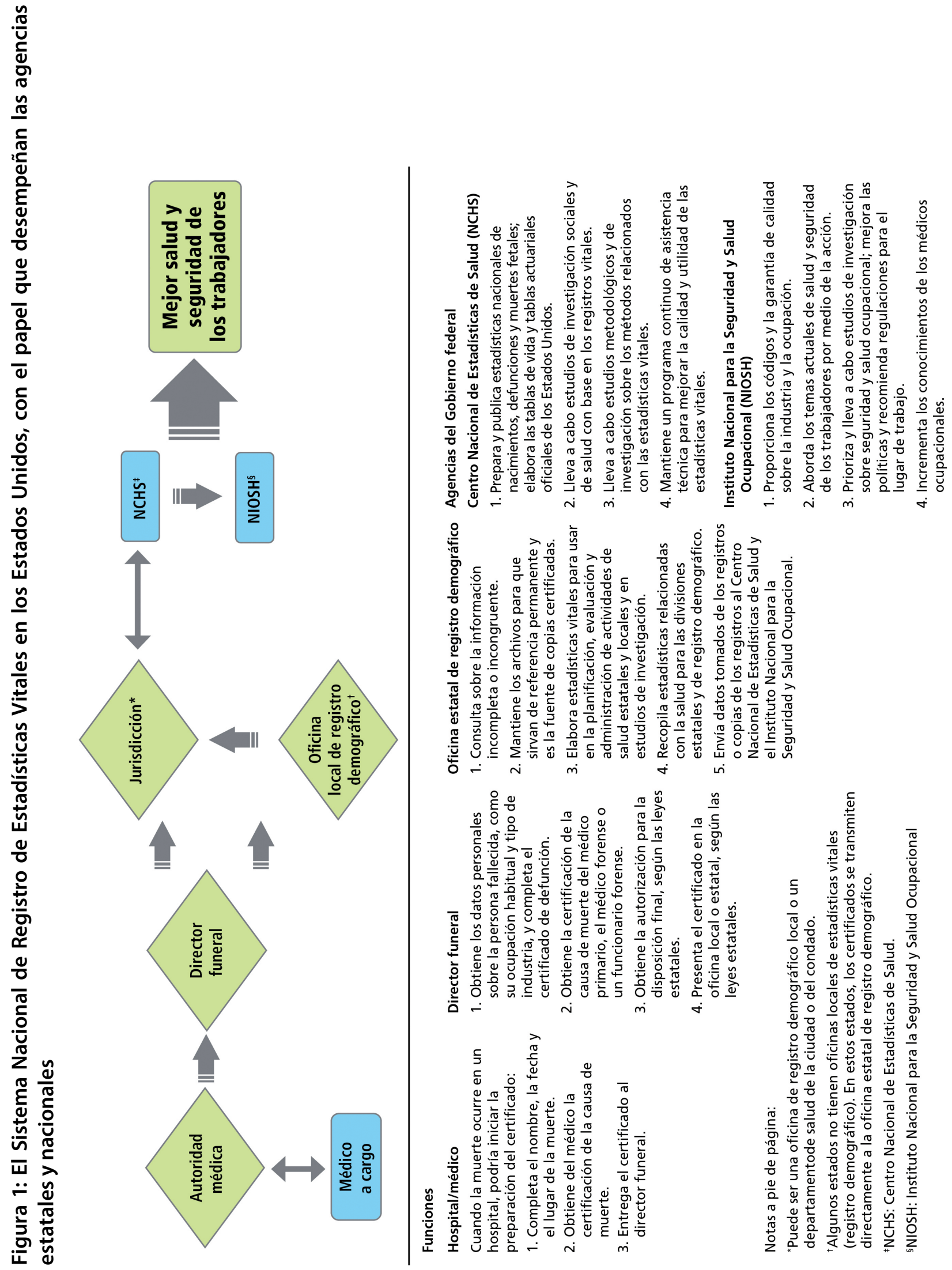


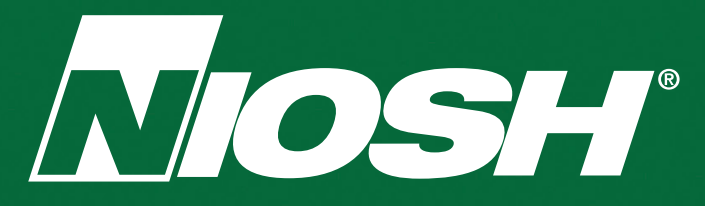

Promoción de lugares de trabajo productivos mediante las investigaciones sobre seguridad y salud

DHHS (NIOSH) Publicación No. 2012-149spa (revisado 01/2021) DOI: https://doi.org/10.26616/NIOSHPUB2012149sparevisado012021 